\title{
Anatomia foliar de plantas transgênicas e não transgênicas de Carica papaya L. (Caricaceae)
}

\author{
Marcos Vinicius Leal-Costa ${ }^{1,2,4}$, Márcia Munhoz ${ }^{2}$, Paulo Ernesto Meissner Filho ${ }^{3}$, Fernanda Reinert ${ }^{1,2}$, \\ Eliana Schwartz Tavares ${ }^{1,2}$
}

Recebido em 13/08/2009. Aceito em 3/05/2010

\begin{abstract}
RESUMO - (Anatomia foliar de plantas convencionais e transgênicas de Carica papaya L. (Caricaceae)). O mamoeiro, Carica papaya L. (Caricaceae) é uma espécie americana, cujos frutos são largamente consumidos em todo mundo. Devido às perdas de produção provocadas por viroses e a dificuldade em controlá-las por métodos convencionais, a espécie tem sido alvo de pesquisas de melhoramento genético envolvendo transgenia para resistência a vírus. $\mathrm{O}$ presente trabalho descreve a anatomia foliar de plantas de mamoeiro convencional e transgênico resistente ao vírus da mancha anelar-Papaya ringspot virus (PRSV) com inserção da capa protéica viral. As duas cultivares apresentam pecíolo com endoderme e fibras pericíclicas. As folhas são hipoestomáticas e dorsiventrais, com laticíferos acompanhando os feixes vasculares e grande concentração de idioblastos com drusas de oxalato de cálcio. A epiderme é glabra, possuindo estômatos anomocíticos e anisocíticos, com células de paredes anticlinais retas na face adaxial e levemente sinuosas na face abaxial. O presente trabalho concluiu que o processo de transformação genética não alterou as características anatômicas das folhas de C. papaya, servindo de subsídio para avaliação da conformidade anatômica da cultivar transgênica.

Palavras-chave: anatomia de plantas cultivadas, anatomia de plantas geneticamente modificadas, mamoeiro
\end{abstract}

\begin{abstract}
Leaf anatomy of genetically modified and wild-type Carica papaya L. (Caricaceae)). Papaya, Carica papaya L. (Caricaceae), is an American species, consumed worldwide. A major limitation to papaya production is attack by viruses, like the papaya ringspot virus (PRSV). Papaya has been genetically modified to increase its resistance to PRSV. The aim of this research was to compare the leaf anatomy of wild-type and genetically modified (GM) C. papaya plants to evaluate the influence of genetic modification on leaf anatomy. Wild-type and GM plants showed petiole with endodermis and pericycle fibers. The leaves are hypostomatic and dorsiventral, with laticifers along vascular system and abundant druses of calcium oxalate. The epidermis was glabrous and presented anomocytic and anisocytic stomata, straight anticlinal walls on the adaxial face and sinuous on the abaxial face. Anatomical differences between wild-type and GM C. papaya leaves were not observed. These data contribute to risk assessments regarding the anatomical conformity of GM plants.

Key words: anatomy of culturing plants, anatomy of genetically modified plants, Papaya
\end{abstract}

\section{Introdução}

O mamoeiro (Carica papaya L.) é uma planta que produz frutos de alto valor nutritivo, durante o ano todo e em abundância, representando atividade de grande expressão econômica no Brasil (Souza Jr., 2000). A produção brasileira chegou a cerca de 1.900 .000 toneladas em 2008, aproximadamente $21 \%$ da produção mundial (FAOSTAT, 2010). Tal valor poderia ser maior não fossem as numerosas pragas que afetam a cultura (Souza Jr. 2000).

O maior problema fitossanitário enfrentado no cultivo do mamoeiro é a mancha anelar causada pelo vírus Papaya ringspot virus (PRSV). Técnicas modernas de engenharia genética possibilitaram a produção da primeira planta de mamoeiro modificada geneticamente para resistência ao PRSV na década de 90, expressando o gene da capa protéica de um isolado havaiano. Entretanto, foi descoberto que essas plantas apresentavam susceptibilidade a infecções por outros isolados de PRSV, inclusive os brasileiros. A Embrapa, desde 2003, utiliza um gene da capa protéica de um isolado do PRSV coletado na Bahia, para produzir plantas de C. papaya geneticamente modificadas $(\mathrm{GM})$ resistentes às condições brasileiras (Carmo \& Souza Jr. 2003). Essa variedade GM está em fase de estudo de campo em Cruz das Almas, Bahia. O sucesso dessa cultivar poderá representar maior rentabilidade com o cultivo do mamão e menor demanda por novas áreas de plantio.

Da mesma forma que ocorre com outras espécies cultivadas, a descrição anatômica do mamoeiro é de grande interesse pelo crescente surgimento de novas cultivares GM. Estudos anatômicos oferecem material de referência para verificação de conformidade de indivíduos transformados, sendo uma ferramenta de controle da qualidade do processo de transformação (Wilson et al. 2004). Com o objetivo de contribuir com a caracterização de variedades de mamoeiro de interesse econômico, o presente trabalho descreve a anatomia foliar comparada da cultivar Sunrise solo convencional e transgênica, visando oferecer subsídios à avaliação de conformidade morfológica.

\section{Material e métodos}

Os mamoeiros transgênicos foram obtidos por biobalística para resistência ao PRSV na Universidade de Cornell nos Estados Unidos em um trabalho de parceria com a Embrapa, com a introdução do gene da capa protéica do vírus (Souza Jr. \& Gonsalves 1999). O trabalho aqui descrito

\footnotetext{
1 Universidade Federal do Rio de Janeiro,Instituto de Biologia, Departamento de Botânica, Lab. de Anatomia Vegetal, CCS, Rio de Janeiro, RJ, Brasil

2 Programa de Pós-graduação em Biotecnologia Vegetal

3 Embrapa Mandioca e Fruticultura Tropical, Cruz das Almas, BA, Brasil

4 Autor para correspondência: mlealcosta@gmail.com
} 
foi realizado em indivíduos adultos provenientes desse processo de transformação genética em fase de teste de campo em Cruz das Almas na Bahia. Folhas plenamente desenvolvidas foram coletadas e conservadas em álcool $70 \%$. Ao todo foram coletadas cinco folhas de plantas convencionais e cinco folhas de plantas transgênicas, uma folha por plantas, todas do sétimo nó.

Cortes transversais, em micrótomo de Ranvier, foram efetuados nas regiões proximal, mediana e distal do pecíolo, assim como nos terços basal, médio e apical da lâmina foliar. Nestas, as observações foram realizadas na nervura principal. Os cortes foram clarificados, desidratados, corados em solução alcoólica de azul de astra a 1\% e safranina a 1\% (9:1) e montados em bálsamo do Canadá. Fragmentos da epiderme, entre a nervura principal e o bordo, foram dissociados de acordo com Jeffrey (Johansen 1940), desidratadas, coradas com safranina 1\% em solução alcoólica $50 \%$ (Johansen 1940) e utilizadas para confecção de lâminas permanentes e semipermanentes.

Para os testes histoquímicos foram empregados os seguintes reagentes: para amido, lugol (Johansen 1940); para lipídios, Sudan III (Sass 1951); e para verificar a natureza dos cristais, ácido nítrico $10 \%$ (Chamberlain 1932).

As fotomicrografias foram feitas com auxílio de microscópio óptico (Bausch \& Lomb DynaZoom Photo Binocular) equipado com câmara fotográfica e os desenhos, com microscópio óptico (Zeiss Standard) equipado com câmara clara.
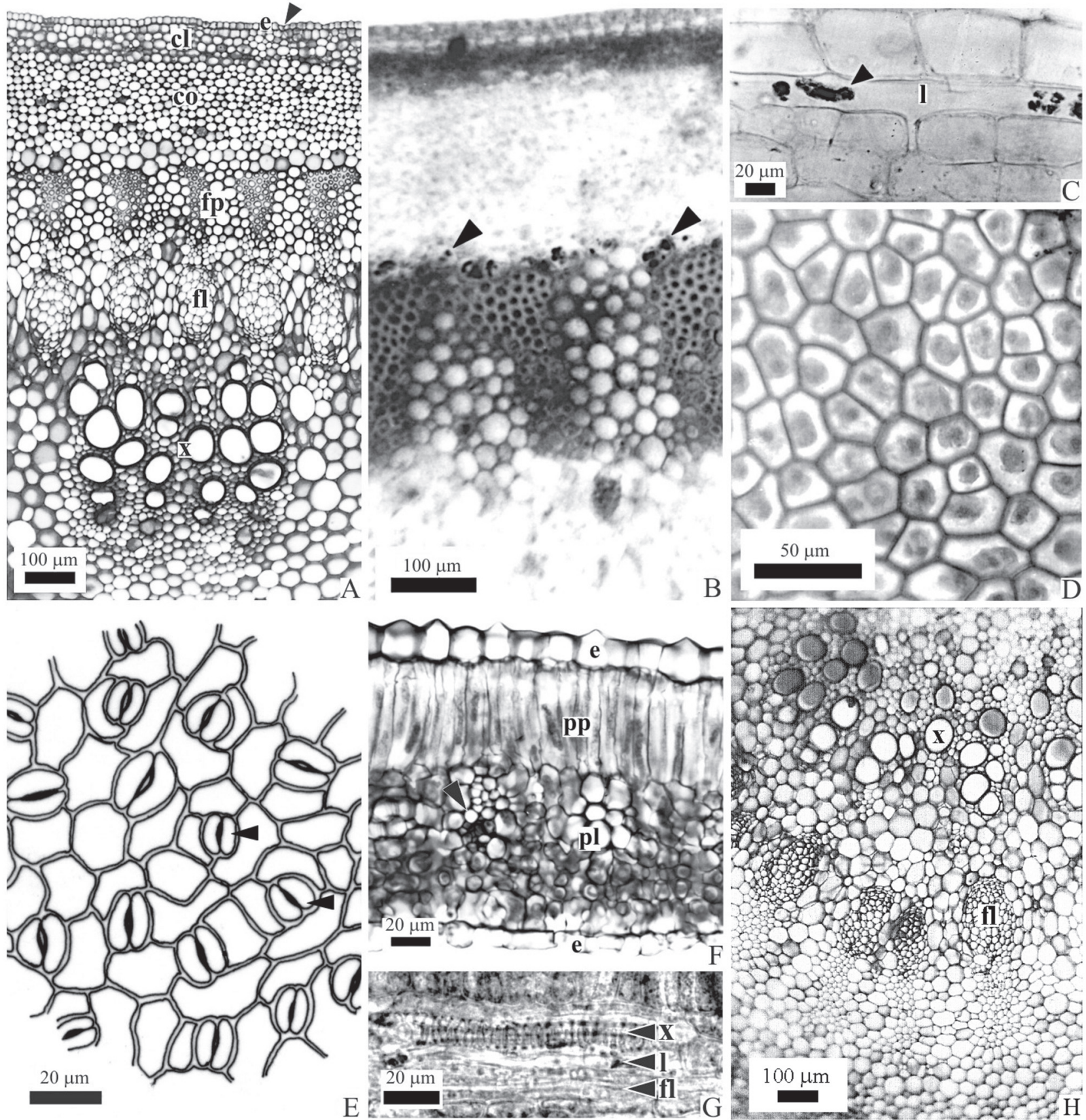

Figura 1. Secções da folha de Carica papaya L. A e B - secções transversais da porção mediana do pecíolo; ponta de seta, em A, destaca estômato, em B, endoderme com amido. C - secção longitudinal do pecíolo, com destaque para laticífero e seu conteúdo (ponta de seta). D - vista frontal da face adaxial da epiderme da lâmina foliar. E - desenho da vista frontal da face abaxial da epiderme da lâmina foliar com destaque para estômatos anisocíticos (pontas de seta). F e G - secções transversais da lâmina foliar, com destaque para laticíferos (pontas de seta). $\mathrm{H}$ - secção transversal da nervura principal. cl - parênquima clorofiliano, co - colênquima do tipo angular, e-epiderme, fl-floema, fp-fibras pericíclicas, 1 - laticífero, x - xilema. A, D, F e H - planta geneticamente modificada; B, C, E e G-planta convencional. 


\section{Resultados e discussão}

Tanto na cultivar convencional quanto na GM, o pecíolo possui secção cordiforme junto ao caule, tornando-se cilíndrico nas porções mediana e distal. As duas cultivares apresentam pecíolo com epiderme glabra e estômatos no mesmo nível das demais células (Fig. 1A). Metcalfe \& Chalk (1950) registraram a ocorrência de tricomas glandulares claviformes no pecíolo de Carica papaya. No entanto, Fisher (1980) registrou que tais tricomas ocorrem na fase juvenil das folhas, caducando conforme as folhas se expandem. Abaixo da epiderme são observadas cerca de cinco camadas de células de clorênquima e, abaixo destas, colênquima do tipo angular (Fig. 1A). Abaixo do colênquima, circundando os tecidos vasculares, observa-se endoderme caracterizada pela presença de grãos de amido (Fig. 1B), a qual não havia sido relatada anteriormente (Yin 1941; Metcalfe \& Chalk 1950; Fisher 1980). Na porção mediana do pecíolo, abaixo da endoderme, observa-se um anel esclerenquimático, formado por fibras alternadas com parênquima lignificado, formando o periciclo (Fig. 1A, B). O sistema vascular é constituído de feixes colaterais com xilema e floema separados por células parenquimáticas (Fig. 1A). Laticíferos articulados podem ser observados entre o floema e o xilema (Fig. 1C), de onde se ramificam para todos os tecidos do pecíolo. O conteúdo dos laticíferos é evidenciado com Sudan III, tomando coloração avermelhada, denotando conter substâncias de natureza lipofílica.

Nas duas cultivares, na lâmina foliar e em vista frontal, observa-se epiderme com paredes anticlinais retas na face adaxial e levemente sinuosas na abaxial (Fig. 1D, E). Estômatos são observados exclusivamente na face abaxial, podendo ser anisocíticos ou anomocíticos (Fig. 1E). Estômatos restritos à face abaxial foram observados anteriormente em C. papaya (Metclafe \& Chalk 1950; Fisher 1980; Shai et al. 1986), porém, só do tipo anomocítico.

Em secção transversal, nas duas cultivares, observa-se epiderme uniestratificada. Ambas cultivares apresentam mesofilo do tipo dorsiventral, no qual o parênquima paliçádico é composto por uma ou raramente duas camadas de células (Fig. 1F). O parênquima lacunoso compõe-se de células de tamanho e formas variados (Fig. 1F). Neste, observa-se cristais de oxalato de cálcio em forma de drusas (Fig. 1F). Tais características já foram observadas em folhas de mamoeiro (Metcalfe \& Chalk 1950; Fisher 1980; Shai et al. 1986). Porém, só Fisher (1980) citou a segunda camada de parênquima paliçádico aparecendo raramente. Laticíferos foram observados acompanhando os feixes vasculares e seu conteúdo evidenciado pelo Sudan III (Fig. 1G). A disposição desses laticíferos está de acordo com observações anteriores (Metcalfe \& Chalk 1950; Shai et al. 1986). A nervura principal possui contorno biconvexo. Abaixo da epiderme são observadas células parenquimáticas e, abaixo destas, colênquima do tipo angular (Fig. 1H). No terço basal, o sistema vascular é constituído de feixes colaterais esparsos e de células floemáticas. Nos terços mediano e apical, o xilema constitui-se de menor número de feixes, mais agrupados, enquanto o floema permanece distribuído em grupos pelo perímetro da nervura (Fig. 1H). Como no pecíolo, xilema e floema são separados por células parenquimáticas (Fig. 1H). As mesmas características foram observadas por Yin (1941) e Fisher (1980), e não diferiram entre plantas convencionais e transgênicas.

\section{Conclusão}

As características anatômicas foliares a serem destacadas na caracterização do mamoeiro são (1) a endoderme no pecíolo, evidente com grãos de amido e não antes descrita; (2) os feixes vasculares colaterais; (3) os laticíferos que acompanham os feixes vasculares, cujo conteúdo sugere apresentar substâncias de natureza lipídica; e (4) estômatos do tipo anomocitico e anisocitico, este último pela primeira vez descrito para espécie. Plantas convencionais e transgênicas mostraram-se idênticas garantindo sua conformidade do ponto de vista da anatomia foliar.

\section{Agradecimentos}

À CAPS pela concessão de bolsa aos dois primeiros autores.

\section{Referências bibliográficas}

Carmo, L.S.T. \& Souza Jr, M.T. 2003. Transformação Genética de Mamoeiro - 15 anos de sucesso. Brasília, Embrapa-SPI / Embrapa-Cenargen.

Chamberlain, M.E. 1932. Methods in plant histology. Chicago. The University of Chicago Press.

FAOSTAT. http://faostat.fao.org/site/567/DesktopDefault. aspx?PageID=567\#ancor (Acesso em: 28/04/2010).

Fisher, J.B. 1980. The vegetative and reproductive structure of papaya (Carica papaya). Lyonia 1: 191-208.

Johansen, D.A. 1940. Plant microtechnique. New York, McGraw-Hill Book Co. Inc.

Metcalfe, C.R. \& Chalk, L. 1950. Anatomy of dicotyledons Vol. I. Oxford, Clarendon Press.

Sass, J.E. 1951. Botanical microtechnique. Ames, The Iowa State College Press.

Shai, A.; Allan, P.; Gilliland, M. \& Savage, M. J. 1986. Anatomy and ultrastructure of Carica papaya leaves. South African Journal of Botany 52: 372-378

Souza Jr, M.T. \& Gonsalves, D. 1999. Genetic engineering resistance to plant virus diseases: an effort to control papaya ringspot potyvirus in Brazil. Fitopatologia Brasileira 24: 485-502.

Souza Jr, M.T. 2000. Mamão transgênico. Biotecnologia, ciência \& desenvolvimento. 2, 132-137.

Wilson, A., Lathan, J. \& Steinbrecher, R. 2004. Genome scrambling myth or reality? Transformation-Induced Mutations in Transgenic Crop Plants. http://www.econexus.info/publications.html (Acesso em 25/05/2009).

Yin, H.C. 1941. Studies on the nyctinastic movement of the leaves of Carica papaya. American Journal of Botany 28: 250-261. 